\title{
Relationships between radiological and biochemical evidence of rickets in Asian schoolchildren
}

\author{
A. Abdul-Motaal ${ }^{1}$, G. Gettinby ${ }^{1}$, W.B. McIntosh ${ }^{2}$, G.R. Sutherland ${ }^{3}$ and M.G. \\ Dunnigan $^{4}$
}

${ }^{1}$ Department of Mathematics, University of Strathclyde, Glasgow and Departments of ${ }^{2}$ Biochemistry, ${ }^{3}$ Radiology and ${ }^{4}$ Medicine, Stobhill General Hospital, Glasgow, UK.

\begin{abstract}
Summary: One hundred Asian schoolchildren provided evidence of the relationships between radiological and biochemical evidence of rickets in a vitamin D-deficient population. In a retrospective study of the X-rays of 56 children the variables serum alkaline phosphatase, inorganic phosphorus and age provided a discriminant function which correctly classified 10 of 11 children with radiological evidence of rickets and 44 of 45 children with negative or marginally abnormal $X$-rays. When the discriminant function was applied to a prospective study of $\mathbf{4 4}$ children, three children with radiological evidence of rickets were correctly classified together with 38 of the remaining 41 children with negative or marginally abnormal X-rays. Serum alkaline phosphatase was the most important variable in the discriminant analysis, followed by serum inorganic phosphorus and age. Low levels of serum 25-hydroxy vitamin D (25$\mathrm{OHD)}$ are of little value in predicting the severity of radiological evidence of rachitic bone disease in a vitamin D-deficient population.
\end{abstract}

\section{Introduction}

Except for a study of sub-clinical vitamin D deficiency in infants (Richards et al., 1968), there are no published studies of the relationships between the radiological and biochemical abnormalities found in rickets. The presence of rickets in the Glasgow Asian community (Dunnigan et al., 1981) has allowed an assessment of the value of serum calcium (corrected for albumin), inorganic phosphorus, alkaline phosphatase and 25-hydroxy-vitamin D (25-OHD) in predicting the presence of radiological rickets in Asian schoolchildren.

\section{Materials and methods}

\section{Patients}

In 1979, 56 Asian children between 8 and 16 years of age had X-rays of both knees. The children were selected from a previous study of 189 children from a

A. Abdul-Motaal, B.Sc.; G. Gettinby, B.Sc., D.Phil.; W.B. McIntosh, F.I.M.L.S.; G.R. Sutherland, F.R.C.P., F.R.C.R.; M.G. Dunnigan, M.D., F.R.C.P.

Correspondence: M.G. Dunnigan, Stobhill General Hospital, Glasgow G21 3UW.

Accepted: 27 September 1984 single general practice carried out between January and May 1979 to minimize seasonal variation in serum 25-OHD levels (Dunnigan et al., 1981). The sample consisted of children with abnormal levels of serum calcium, inorganic phosphorus or alkaline phosphatase, possible borderline elevations of serum alkaline phosphatase only and normal routine biochemistry (see below).

The discriminant function derived retrospectively from the biochemical and X-ray findings in these children was evaluated in a prospective study of 44 Asian children who had X-rays of both knees in 1982. These children were selected from a study of 192 children from two general practices carried out between January and May 1982 and had either abnormal levels of serum calcium, inorganic phosphorus or alkaline phosphatase or possible borderline elevations of serum alkaline phosphatase only (see below).

\section{Biochemical methods}

A blood sample was taken from each child in the general practitioner surveys carried out in 1979 and 1982; serum was separated within half an hour of venepuncture. Serum calcium, inorganic phosphorus, alkaline phosphatase and plasma albumin were measured on an SMA6 plus Technicon AutoAnalyzer. 
Observed serum calcium was corrected for serum albumin by the formula of Kennedy et al. (1975). Serum 25-OHD was measured by a competitive binding technique with the addition of preparative chromatography (Belsey et al., 1974).

\section{Reference ranges employed}

Values of serum 25-OHD below $5 \mathrm{ng} / \mathrm{ml}$, corrected serum calcium below $2.22 \mathrm{mmol} / 1$ and serum inorganic phosphorus below the normal range for age and sex given by Round (1973) between 8-16y $(1.2-0.97 \mathrm{mmol} / 1)$ were regarded as abnormal. Serum alkaline phosphatase levels rise to between three and four times normal adult levels at the pubertal growth spurt and return to adult levels at about $16 \mathrm{y}$ in girls and about $18 \mathrm{y}$ in boys. Based on our own laboratory experience and that of two large recent studies of reference ranges in Spanish and French children (Schiele et al., 1983; Gomez et al., 1984), levels of alkaline phosphatase above $400 \mathrm{IU} / 1$ representing approximately the 95th (Schiele et al., 1983) or the 97th (Gomaz et al., 1984) percentile of the peak associated with the pubertal growth spurt were regarded as abnormal (adult reference range 40-115IU/1). Levels of between 300-399IU/1 were regarded as marginally elevated to take account of the lower upper limits of normal in children before and following the pubertal growth spurt; these levels were not found to be associated with significant evidence of rachitic bone disease on X-ray (see below).

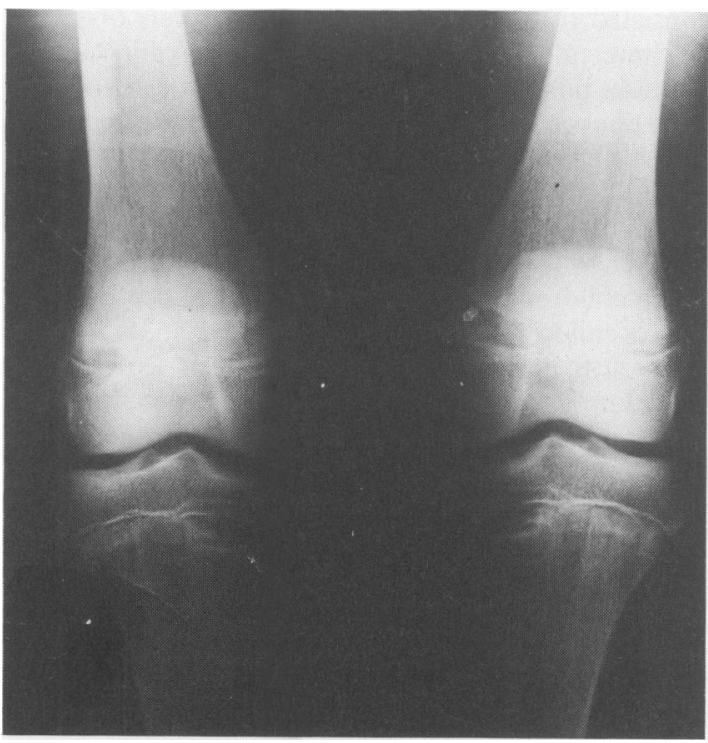

Figure 1 Radiograph of knees showing advanced rickets. There is gross widening of all the epiphyseal plates.

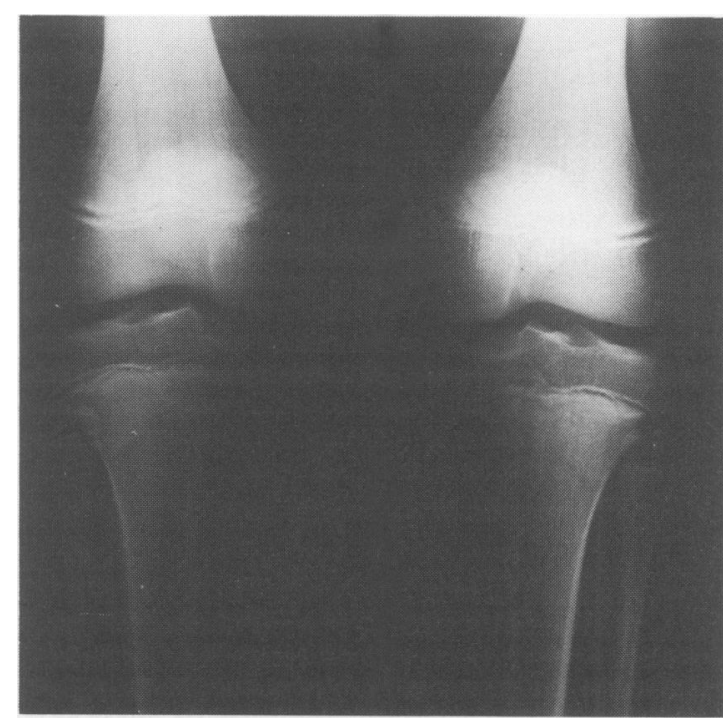

Figure 2 Radiograph of knees showing 'marginal' changes of rickets. There is slight irregularity and some widening of the medial portions of the epiphyseal plates of the upper ends of the tibiae.

\section{Radiological assessment}

In order to examine the possible relationships of the radiological abnormalities found in rickets to abnormal levels of serum calcium, inorganic phosphorus, alkaline phosphatase and 25-OHD, the $56 \mathrm{X}$-ray films of the knees of the children comprising the retrospective study were reviewed by the participating radiologist (GRS). The abnormalities reviewed included the width and irregularity of the epiphyseal plates, the presence of sclerotic bands in the metaphysis and distal diaphysis and loss of trabecular definition. Only an increase in the visually assessed width of the epiphyseal plate bore a relationship to biochemical evidence of rickets. Direct measurement of plate width proved impractical because of the anatomical variation in thickness and regularity of the epiphyseal plates in this age group.

The epiphyseal plates of the knee joints were then assessed blindly on four separate occasions in random order and judged to be abnormally widened and irregular (rachitic; Figure 1), to show marginal widening only ('marginal' rickets; Figure 2) or to be within normal limits (non-rachitic).

\section{Statistical methods}

Tests of multi-normality were carried out on the data using Mardia's test and graphical techniques (Gnadesikan, 1977; Healy, 1968). The F-test (Harris, 
1975) was used to compare the covariance matrices. From the retrospective study, discriminant analysis was employed to predict the rachitic grade on X-ray using single biochemical variables and the child's age. Stepwise discriminant analysis was then used to obtain a weighted combination of the biochemical variables and age which best separated patients in each rachitic category. This discriminant function was applied to the data from the children studied prospectively. The analysis was undertaken using the BMDP statistical package (Dixon, 1981).

\section{Results}

\section{Retrospective study}

Abnormally low levels of serum 25-OHD were present in $27(48 \%)$ of the 56 children whose X-rays were examined retrospectively. Abnormally low levels of corrected serum calcium and inorganic phosphorus and abnormally high levels of alkaline phosphatase were present in $25(45 \%)$ of the 56 children. Twenty one children $(37.5 \%)$ also had possible borderline elevations of serum alkaline phosphatase only. Eleven (44\%) of the 25 children with abnormal routine biochemistry showed definite radiological evidence of rickets. No child with normal levels of serum calcium, inorganic phosphorus or alkaline phosphatase or with borderline elevations of alkaline phosphatase only showed radiological evidence of rickets. Eight children showed 'marginal' rickets and $37 \mathrm{X}$-rays were judged to be non-rachitic.

Initial discriminant analysis could not separate children with 'marginal' rickets from those with nonrachitic X-rays. The two categories were therefore combined in the final analysis. Mean levels of serum calcium, inorganic phosphorus, calcium-phosphorus product, alkaline phosphatase, 25-OHD and age for the rachitic and non-rachitic/'marginal' categories are shown in Table $\mathrm{I}$.

Covariance matrices were not significantly different and the distribution was consistent with a multinormal distribution. Discriminant analysis using single variables (Table II) showed that serum alkaline phosphatase discriminated best between children with rachitic and non-rachitic/'marginal' X-rays. The calcium-phosphorus product and serum inorganic phosphorus were the second and third most discriminating variables. Serum calcium, 25-OHD and age had high mean error rates. When the variables were combined, stepwise discriminant analysis using untransformed data gave the following optimal discriminant function:-

$\mathrm{Z}$ (discriminant score) $=\mathbf{0 . 0 2 5 5}$ (alkaline phosphatase) -4.93 (inorganic phosphorus) - 0.294 (age) 4.242

This function led to one false positive and one false negative classification of the $56 \mathrm{X}$-rays studied retrospectively (Table III). Standardized coefficients (S.C.) for each of the variables in this function confirmed

Table I Mean values of variables used to predict the presence or absence or radiological rickets (retrospective study)

\begin{tabular}{|c|c|c|c|c|c|c|c|}
\hline \multirow[b]{3}{*}{ Variable } & \multicolumn{7}{|c|}{$X$-ray } \\
\hline & \multicolumn{3}{|c|}{$\begin{array}{c}\text { Non-rachitic/ } \\
\text { 'marginal' rickets }\end{array}$} & & \multicolumn{3}{|c|}{ Rachitic } \\
\hline & Mean & \pm & s.d. & & Mean & \pm & s.d. \\
\hline Calcium (mmol/1) & 2.31 & \pm & 0.12 & & 2.19 & \pm & 0.24 \\
\hline Inorganic phosphorus $(\mathrm{mmol} / \mathrm{l})$ & 1.50 & \pm & 0.24 & & 1.12 & \pm & 0.22 \\
\hline Calcium $\times$ phosphorus & 3.47 & \pm & 0.65 & & 2.44 & \pm & 0.52 \\
\hline Alkaline phosphatase (IU/1) & 374.24 & \pm & 99.9 & & 665.6 & \pm & 158.0 \\
\hline 25-OHD (ng/ml). & 7.45 & \pm & 5.18 & & 4.88 & \pm & 3.15 \\
\hline Age (y) & 11.49 & \pm & 2.59 & & 12.87 & \pm & 1.45 \\
\hline
\end{tabular}

\section{Reference ranges}

Serum calcium (corrected for albumin) : $2.20-2.60 \mathrm{mmol} / 1$

Serum inorganic phosphorus (children $8-16 \mathrm{y}): \quad 1.20-0.97 \mathrm{mmol} / 1$

Serum alkaline phosphatase (children 8-16 y) : 40-400 IU $/ 1^{*}$

Serum 25-OHD

* Peak level associated with pubertal growth spurt; for more detailed information on age and sex-related levels of alkaline phosphatase in children using the methodology employed in the present study see Schiele et al. (1983) and Gomez et al. (1984). †Conversion: traditional to SI units $25-0 H D:-1 \mathrm{ng} / \mathrm{ml} \bumpeq 2.5 \mathrm{nmol} / 1$. 
Table II False positive and negative misclassifications using single variable discriminant analysis to predict the presence or absence of radiological rickets (retrospective study)

\begin{tabular}{|c|c|c|c|c|c|}
\hline \multirow{3}{*}{ Variable } & \multicolumn{4}{|c|}{$X$-ray } & \multirow{3}{*}{$\begin{array}{c}\text { Total } \\
\text { error } \\
\text { rate } \\
\%\end{array}$} \\
\hline & \multicolumn{2}{|c|}{$\begin{array}{c}\text { Non-rachitic } \\
\text { 'marginal' rickets } \\
\text { False + ve }\end{array}$} & \multicolumn{2}{|c|}{$\begin{array}{c}\text { Rachitic } \\
\text { False - ve }\end{array}$} & \\
\hline & $\mathbf{n}$ & $\%$ & $\mathbf{n}$ & $\%$ & \\
\hline Alkaline phosphatase (IU/1) & $1 / 45$ & 2.2 & $3 / 11$ & 27.3 & 7.1 \\
\hline Calcium $\times$ phosphorus & $3 / 45$ & 6.6 & $3 / 11$ & 27.3 & 10.7 \\
\hline Inorganic phosphorus (mmol/1) & $4 / 45$ & 8.8 & $4 / 11$ & 36.4 & 14.3 \\
\hline 25-OHD (ng/ml) & $0 / 45$ & 0.0 & $11 / 11$ & 100.0 & 19.6 \\
\hline Calcium (mmol/1) & $2 / 45$ & 4.4 & $10 / 11$ & 90.9 & 21.4 \\
\hline Age & $0 / 45$ & 0.0 & $11 / 11$ & 100.0 & 19.6 \\
\hline
\end{tabular}

that serum alkaline phosphatase $($ S.C. $=2.88)$ was the most important variable followed by serum inorganic phosphorus (S.C. $=1.18$ ) and age $($ S.C. $=0.71)$. Serum 25-OHD provided poor discrimination and did not appear in the initial function. When age was omitted, a second function was obtained which included serum 25-OHD:-

$\mathrm{Z}$ (discriminant score) $=\mathbf{0 . 0 2 3}$ (alkaline phosphatase) - 4.961 (inorganic phosphorus) - 0.1 (25-OHD) 5.957

This discriminant function gave one false positive and two false negative classifications and was judged less satisfactory than the first function (Table III). Standardized coefficients showed that serum alkaline phosphatase $($ S.C. $=2.6)$ remained the most significant variable followed by serum inorganic phosphorus $($ S.C. $=1.19)$ and serum 25-OHD (S.C. $=0.49)$.
Prospective study

Abnormally low levels of serum 25-OHD were present in $13(30 \%)$ of the 44 children examined prospectively. Ten children $(23 \%)$ had abnormally low levels of corrected serum calcium and inorganic phosphorus or abnormally high levels of alkaline phosphatase. The remaining 34 children had possible borderline elevations of serum alkaline phosphatase only. Three of theo 10 children $(30 \%)$ with abnormal routine biochemis try had definitely rachitic X-rays. No child with a borderline elevation of serum alkaline phosphatase only showed radiological evidence of rickets. Nine children showed 'marginal' radiological abnormalities and $32 \mathrm{X}$-rays were judged to be normal. The reduced prevalence of radiological rickets in this study compared with the retrospective study was due to increased supplement consumption following the Greater Glasgow Health Board's campaign against

Table III False positive and negative misclassifications using stepwise discriminant analysis to predict the presence or absence of radiological rickets in both the retrospective and prospective studies (R.S. and P.S.)

\begin{tabular}{|c|c|c|c|c|c|c|}
\hline \multirow[b]{2}{*}{$\begin{array}{l}\text { Study and } \\
\text { sample size } \\
\text { (n) }\end{array}$} & \multirow[b]{2}{*}{ Variables* } & \multicolumn{4}{|c|}{$X$-ray } & \multirow[b]{2}{*}{$\begin{array}{c}\text { Total } \\
\text { error } \\
\text { rate } \\
\%\end{array}$} \\
\hline & & \multicolumn{2}{|c|}{$\begin{array}{l}\text { Non-rachitic } \\
\text { 'marginal' rickets } \\
\text { False + ve }\end{array}$} & \multicolumn{2}{|c|}{$\begin{array}{c}\text { Rachitic } \\
\text { False - ve }\end{array}$} & \\
\hline $\begin{array}{l}\text { R.S. (56) } \\
\text { R.S. (56) } \\
\text { P.S. (44) }\end{array}$ & $\begin{array}{c}\text { AP, P, Age } \\
\text { AP, P, 25-OHD } \\
\text { AP, P, Age }\end{array}$ & $\begin{array}{l}1 / 45 \\
0 / 45 \\
3 / 41\end{array}$ & $\begin{array}{l}2.2 \\
0.0 \\
7.3\end{array}$ & $\begin{array}{c}1 / 11 \\
2 / 11 \\
0 / 3\end{array}$ & $\begin{array}{r}9.1 \\
18.2 \\
0.0\end{array}$ & $\begin{array}{l}3.6 \\
3.6 \\
6.8\end{array}$ \\
\hline
\end{tabular}

*AP-Serum alkaline phosphatase (IU/1)

$\mathrm{P}$-Serum inorganic phosphorus (mmol/1)

25-OHD - Serum 25-hydroxyvitamin D (ng/ml) 
rickets which began in 1979 (Dunnigan et al., 1981).

The first discriminant function derived from the retrospective study correctly predicted the rachitic category of all three children with definite radiological evidence of rickets. There were no false negative classifications. There were three false positive classifications; these three children had been categorized as having 'marginal' rickets on X-ray and all three had abnormal levels of serum calcium, inorganic phosphorus or alkaline phosphatase.

\section{Discussion}

In a study of sub-clinical rickets in Glasgow infants, Richards et al. (1968) described loss of bony definition and sclerotic bands in the metaphysis which were designated as 'minimal active rickets' and 'minimal healing rickets' respectively and regarded as evidence of sub-clinical vitamin D deficiency. The authors found a 'weak relationship' (which was not quantified statistically) between these changes and elevated serum alkaline phosphatase levels. No other biochemical parameters of vitamin $\mathrm{D}$ deficiency were considered. No other studies of the relationships between biochemical and radiological evidence of rickets appear to have been reported.

In the present study an increase in the overall assessed width of the epiphyseal plates bore a highly significant relationship to the dependent variables examined. Serum alkaline phosphatase was most closely related to the severity of radiological rickets and a discriminant function using serum alkaline phosphatase, inorganic phosphorus and the child's age predicted the rachitic category of 100 Asian schoolchildren ( 56 retrospectively and 44 prospectively) with a high degree of accuracy. Thirty two of the 100 children from both studies had alkaline phosphatase levels over $400 \mathrm{IU} / 1$. X-ray evidence of rickets was found in one of the ten children (10\%) with levels between $400-499 \mathrm{IU} / 1,9$ of the 18 children $(50 \%)$ with levels between $500-799 \mathrm{IU} / 1$ and in all 4 children $(100 \%)$ with levels over $800 \mathrm{IU} / 1$. Using the method employed in our laboratory, significant rachitic bone disease was thus only seen in children with levels of alkaline phosphatase above the peak associated with the pubertal growth spurt (about four times the upper limit of normal for adults) and was uncommon until levels of over 500IU/1 were obtained (about five times the upper limit of normal for adults).

\section{References}

BELSEY, R.E., DE LUCA, H.C. \& POTTS, J.T. (1974). A rapid assay for 25-OHD vitamin $\mathrm{D}_{3}$ without preparative chromatography. Journal of Clinical Endocrinology and Metabolism, 38, 1046.
Total serum alkaline phosphatase is presumably the best biochemical indicator of the severity of radiological evidence of rachitic bone disease in a vitamin $\mathrm{D}$-deficient population because its bone isoenzyme component reflects osteoblastic proliferation in the rachitic skeleton. Serum inorganic phosphorus and the calcium-phosphorus product (which was a significant single variable but did not appear in the final discriminant function) reflect the solubility product at the epiphyseal calcification front. Age, which was an independent variable in the discriminant function, was associated with accelerated growth velocity during the pubertal growth spurt in many of the samples of schoolchildren examined.

Low serum 25-OHD levels are of little value in predicting the severity of rachitic bone disease in a vitamin D-deficient population as judged by X-ray appearances. Routine measurements of serum alkaline phosphatase, calcium and inorganic phosphorus are sufficient for this purpose.

Naike et al. (1977) found that the serum alkaline phosphatase bone iso-enzyme showed a significant relationship with skeletal radiography in dialysis bone disease. Serum alkaline phosphatase was the most important variable in the diagnosis of histological osteomalacia in adults using a discriminant function which included plasma calcium, inorganic phosphorus and alkaline phosphatase (Peach et al. 1982). These results and the present study confirm that a discriminant function using routine biochemistry can be highly predictive of the severity of both rachitic and osteomalacic bone disease.

The present study should be of value in epidemiological studies of nutritional rickets in vitamin D-deficient populations and to the clinician, biochemist and radiologist concerned with the assessment of the severity of the individual case. The serum 25-OHD assay should be restricted to the assessment of individual or group vitamin D status where this is uncertain.

\section{Acknowledgements}

We are grateful to Drs B.M. Glekin, A. Berkeley and J. Freedman for permission to study patients under their care and to the children for their co-operation. The study was made possible by a grant from the Biomedical Committee of the Scottish Home and Health Department.
DIXON, W.J. (ed.) (1981). BMDP Statistical Soft Ware, University of California Press, Berkeley.

DUNNIGAN, M.G., McINTOSH, W.B., SUTHERLAND, G.R., GARDEE, R., GLEKIN, B., FORD, J.A. \& ROBERTSON, I. 
(1981). Policy for prevention of Asian rickets in Britain: a preliminary assessmentof the Glasgow rickets campaign. British Medical Journal, 282, 357.

GNADESIKAN, R. (1977). Methods for Statistical Analysis of Multivariate Observations. Wiley: New York.

GOMEZ, P., COCA, C., VARGAS, C., ACHILLO, J. \& MARTINEZ, A. (1984). Normal reference intervals for 20 biochemical variables in healthy infants, children and adolescents. Clinical Chemistry, 30/3, 407.

HARRIS, R.J. (1975). A Primer of Multivariate Statistics. Academic Press: New York.

HEALY, M.J.R. (1968). Multivariate normal plotting. Applied Statistics, 17, 157.

KENNEDY, A.C., ALLAN, B.F., BOYLE, I.T., ROONEY, P.J. \& BUCHANAN, W.W. (1975). Abnormalities in mineral metabolism suggestive of parathyroid over-activity in rheumatoid arthritis. Current Medical Research and Opinion, 3, 345.

NAIKE, R.B., GOSLING, P.\& PRICE, C.P. (1977). Comparative study of alkaline phosphatase isoenzymes, bone histology and skeletal radiography in dialysis bone disease. British Medical Journal, 1, 1307.

PEACH, H., COMPSTON, J.E., VEDI, S. \& HARTON, L.W.L. (1982). Value of plasma calcium, phosphate and alkaline phosphatase measurements in the diagnosis of histological osteomalacia. Journal of Clinical Pathology, 35, 625.

RICHARD, I.D.G., HAMILTON, F.M.W., TAYLOR, E.C., SWEET, E.M., BREMNER, E. \& PRICE, H. (1968). A search for sub-clinical rickets in Glasgow children. Scottish Medical Journal, 13, 297.

ROUND, J.M. (1973). Plasma calcium, magnesium, phosphorus and alkaline phosphatase levels in normal British schoolchildren. British Medical Journal, 3, 137.

SCHIELE, F., HENNY, J., HITZ, J., PETITCLERC, C., GUEGUEN, N. \& SIEST, G. (1983). Total bone and liver alkaline phosphatases in plasma: biological variations and reference limits. Clinical Chemistry, 294, 634. 